\title{
Microwave-assisted hydrotropic pretreatment as a new and highly efficient way to cellulosic ethanol production from maize distillery stillage
}

\section{Mikulski Dawid}

Uniwersytet Kazimierza Wielkiego Wydzial Nauk Przyrodniczych

Grzegorz Kłosowski ( $\square$ klosowski@ukw.edu.pl)

Kazimierz Wielki University https://orcid.org/0000-0002-4678-4512

\section{Research}

Keywords: microwave-assisted hydrotropic pretreatment, distillery stillage, cellulosic ethanol, sodium cumene sulfonate

Posted Date: June 19th, 2020

DOI: https://doi.org/10.21203/rs.3.rs-36466/v1

License: (c) (i) This work is licensed under a Creative Commons Attribution 4.0 International License.

Read Full License

Version of Record: A version of this preprint was published at Applied Microbiology and Biotechnology on April 1st, 2021. See the published version at https://doi.org/10.1007/s00253-021-11258-2. 


\section{Abstract}

Background: The development of the second generation ethanol production technology requires new, highly effective methods of pretreatment of lignocellulosic biomass, which reduces lignin content, eliminates fermentation inhibitors, and makes the biomass susceptible to hydrolysis using cellulolytic enzymes. New pretreatment methods should be adapted to the processing of lignocellulosic waste biomass from various industries. One of the problems is the management of grain stillage, which is waste from the production of first generation ethanol.

Results: The aim of the study was to assess the suitability of the combined use of microwave radiation and sodium cumene sulfonate under optimized process conditions for the preparation of maize stillage biomass as a raw material for the production of cellulosic ethanol. The key parameter guaranteeing a high level of lignin removal from biomass (ca. $44 \%$ ) was the concentration of hydrotrope. The highest organic matter extraction from biomass $(67.00 \pm 1.68 \%$ ) was observed for $20 \% \mathrm{v} / \mathrm{v}$ sodium cumene sulfonate, ca. $117 \mathrm{PSI}$ (microwave heating) and $30 \mathrm{~min}$ exposure time. Even at high biomass concentration ( $16 \% \mathrm{w} / \mathrm{v})$ and a cellulose enzyme dose of about $4 \mathrm{FPU} / \mathrm{g}$, maize stillage biomass subjected to microwave-assisted hydrotropic pretreatment was highly susceptible to enzymatic degradation, which resulted in $80 \%$ hydrolysis yield. The stillage biomass processed in this way is a very good raw material for the production of cellulosic ethanol. It is possible to obtain a fermentation medium with a very high glucose concentration (up to $80 \mathrm{~g} / \mathrm{L}$ ), without fermentation inhibitors (such as 5-HMF, furfural, lignin degradation products) and, as a consequence, to reach a very high level of sugar conversion to ethanol, even as much as $95 \%$ of theoretical yield.

Conclusions: Microwave hydrotropic treatment with sodium cumene sulfonate is a very effective way to prepare waste maize stillage biomass for the production of cellulosic ethanol. The method provides a high level of enzymatic degradation of cellulose, leading to a medium with high content of released sugars suitable for bioconversion, which is in line with the assumptions of the second generation ethanol production technology.

\section{Background}

A positive balance of carbon dioxide concentration in the atmosphere and limited resources of fossil fuels necessitate the search for alternative energy sources, the production of which is based on renewable resources and creates a real chance to reduce environmental pollution. Ethanol produced from lignocellulosic raw materials is a biofuel that meets these requirements. The second generation ethanol production is based on waste lignocellulosic biomass, sometimes even solving problems with waste management, therefore it does not compete for raw materials used for food or feed production $[1,2]$. However, the effective use of plant biomass with a complex structure, mainly composed of cellulose, hemicellulose and lignins, requires the use of an effective pretreatment method that would guarantee a reduction of crystalline areas in cellulose, as well as partial degradation of hemicellulose and lignins. At the same time, lignocellulose pretreatment should not lead to the formation of large amounts of 
fermentation inhibitors such as furfural and 5-hydroxymethylfurfural (5-HMF), which are products of sugar dehydration, nor produce phenolic compounds resulting from the degradation of lignins, e.g. vanillin, syringaldehyde, ferulic acid [3, 4]. Methods using elevated temperature and pressure associated with various chemical catalysts, i.e. diluted acids and bases, ionic liquids or organic solvents are the most popular and also the most effective plant biomass pretreatment techniques [5-9]. An effective way to create the necessary pressure is to heat the aqueous biomass suspension with microwaves. Electromagnetic radiation from $0.3 \mathrm{GHz}$ to $300 \mathrm{GHz}$ quickly heats the biomass (without heating the structural elements of the tank in which it is located) and partially disrupts the hydrogen bonds in the cellulose structure through the oscillating motion of the dipoles. A certain limitation is the presence of overheating zones, called "hotspots", which can generate excessive concentrations of sugar dehydration products that adversely affect yeast's fermentation activity [10-12]. The efficiency of baro-thermal treatment of biomass depends on the concentration of the acidic or basic catalyst. Regardless of the type of catalysis, for economic reasons it is advisable to recover acids or bases during the technological process, which is often quite troublesome [3]. Our and other authors' studies clearly pointed to the usefulness of microwave pretreatment in a diluted sulfuric acid environment in the degradation of lignocellulose to simple sugars, which can then be used in bioconversion and biosynthesis processes [11-16].

Alternatively, pretreatment of lignocellulosic biomass can be accomplished using compounds that partially remove lignins limiting the availability of cellulose fibers to cellulolytic enzymes. In the delignification process, hydrotropes, i.e. low molecular weight sodium or potassium salts of benzoic or arylsulfonic acid with a substituted alkyl group are used. Similarly to surfactants, they have an amphiphilic structure and reduce surface tension. However, unlike surfactants, they have smaller hydrophobic parts and do not self-aggregate into micelles [17-19]. The most effective hydrotropes include sodium xylene sulfonate ( $\mathrm{Na}-\mathrm{XS}$ ) and sodium cumene sulfonate ( $\mathrm{NaCS}$ ). These compounds reduce the lignin concentration in plant biomass, depending on its origin, by ca. $38 \%$ in eucalyptus biomass [9] and by ca. $47 \%$ in the mixture of beech and birch chips [20]. A very important aspect of using hydrotropes in the process of lignin extraction from lignocellulosic biomass is the possibility of recovering solutes by diluting the hydrotrope solution, which can be reused after concentration [21]. Hydrotropic delignification is most effective at elevated temperatures and often has to be combined with subsequent baro-thermal treatment in a dilute acid environment. It leads not only to a decrease in lignin concentration, but also to a high level of glucose released during enzymatic hydrolysis of cellulose [1921].

The use of microwave radiation is not limited to heating biomass at the pretreatment stage. Microwaves are also used as a factor supporting delignification with acids and bases, ionic liquids or organic solvents. With properly selected process conditions, microwave treatment combined with the use of dilute sulfuric acid reduced the lignin content in Aloe vera biomass by more than $50 \%$ [22]. Diluted sodium hydroxide together with microwave radiation also successfully delignified the biomass of Prosopis juliflora (lignin content reduction up to 70\%) [23]. In order to reduce the use of chemical reagents that have a negative impact on the natural environment, research is being pursued to find alternative 
substances supporting the lignocellulose pretreatment process. Microwave-assisted delignification can also be carried out using environmentally friendly ionic liquids that can reduce the lignin concentration in biomass by up to $80 \%$, depending on the raw material $[24,25]$.

Effective pretreatment of lignocellulosic biomass, providing cellulose susceptible to hydrolysis, which at the same time does not burden the environment nor generate fermentation inhibitors, is a key element in the production of cellulosic ethanol. Currently, the search for new combinations of physico-chemical methods of pretreatment focuses mainly on the use of environmentally friendly substances that can be used in the recirculation system under elevated pressure. Hydrotropes meet all of the above-mentined conditions. As shown in earlier studies, hydrotropes can be used at the initial stage to intensify subsequent processing, e.g. with diluted inorganic acids $[19,21]$. The aim of the present study was to develop a one-step maize stillage biomass pretreatment method using sodium cumene sulfonate (NaCS) together with microwave radiation to obtain a substrate susceptible to enzymatic hydrolysis of cellulose and maintain a low concentration of fermentation inhibitors. The research included selection of the conditions of microwave hydrotropic delignification (pressure and time of exposure as well as NaCS concentration) providing a maximum level of extraction of biomass components. The biomass with the highest level of lignin extraction was optimized for enzymatic hydrolysis and subsequent alcoholic fermentation to determine the degree of bioconversion of sugars to ethanol. The available literature on the subject lacks reports on hydrotropic delignification using microwave radiation. The authors believe that it is reasonable to combine these two pretreatment methods. The effectiveness of hydrotropes in the delignification process increases with increasing temperature and pressure, which is ensured by microwaves. The biomass obtained in such a process is susceptible to enzymatic hydrolysis. No additional catalysts such as inorganic acids, are required.

\section{Results And Discussion}

\section{Selection of conditions for microwave hydrotropic extraction}

We analyzed the effect of various combinations of conditions of microwave hydrotropic treatment, i.e. NaCS concentration $(0,10,20 \% \mathrm{v} / \mathrm{v})$, exposure time $(10,20,30 \mathrm{~min})$ and pressure $(39,78,117 \mathrm{PSI})$ on the extraction of biomass components, changes in biomass composition (cellulose, hemicellulose and lignin content) and the amount of glucose released from pre-processed biomass as after hydrolysis with cellulases. The experiments showed that effective extraction of components of maize stillage biomass was possible even when only water was used as the solvent ( $0 \% \mathrm{v} / \mathrm{v} \mathrm{NaCS})$. This confirms the effectiveness of microwave treatment in the extraction processes. Lignocellulosic biomass extractives increased with exposure time and increasing pressure (Fig. 1). Higher pressure during the extraction was associated with higher temperature, which promoted dissolution of solid components. The extraction of biomass components also increased with increasing NaCS concentration, as a result of a decrease in the surface tension of the solution used. The highest biomass extractives, $67.00 \pm 1.68 \%$, were observed for 
the highest NaCS concentration (20\% v/v), 30 min exposure time and 117 PSI (Fig. 1). Biomass extractives in this extraction variant were more than $12 \%$ higher compared to $10 \% \mathrm{v} / \mathrm{v} \mathrm{NaCS}$ extraction and more than $20 \%$ higher than with water-only extraction, with the remaining process parameters unchanged (Fig. 1). Against the background of the current state of knowledge, the results showing effects of the combined application of microwaves and hydrotropes in plant biomass extraction are an element of scientific novelty. The positive influence of high temperature and elevated hydrotrope concentration on the extraction process was reported in previous studies. Increased temperature disrupts bonds in lignocellulosic biomass. This effect, in combination with the amphiphilic structure of hydrotropes and their ability to increase the solubility of organic compounds in aqueous solutions, increases the extraction [26]. In our earlier study, we also used the maize stillage biomass as a source of lignocellulose, but the maximum extractives were only $25.56 \pm 1.25 \%$ at $131^{\circ} \mathrm{C}(40.15 \mathrm{PSI})$ with $20 \% \mathrm{v} / \mathrm{v} \mathrm{NaCS}$ [19]. The maximum extraction of biomass components from rice straw using $20 \% \mathrm{v} / \mathrm{v}$ NaCS at $131^{\circ} \mathrm{C}$ was $31.07 \pm$ $2.47 \%$ [21]. In the present study a much higher level of extraction of biomass components using NaCS was achieved due to the combined use of microwave radiation. The usefulness of microwaves in the extraction of biomass components was also confirmed for the $\mathrm{NaOH}$ solution. After vine shoots processing with microwave radiation and $3.1 \% \mathrm{w} / \mathrm{v} \mathrm{NaOH}$ at $125^{\circ} \mathrm{C}$, biomass extractives increased to $54 \%$ [27]. Other authors also confirmed the dependence of extraction on the type and concentration of the solution used for pretreatment. In the microwave assisted treatment of Dragon Fruit, biomass extractives increased from ca. 4 to $11 \%$ and from ca. 7 to over $12 \%$ with increasing concentration of sulfuric acid (from 0.01 to $0.1 \mathrm{~N}$ ) and sodium hydroxide (from 0.01 to $0.1 \mathrm{~N}$ ), respectively [14]. A high level of extraction of vine shoot biomass components (ca. 53\%) was also observed when microwave radiation was used along with $\mathrm{NaOH}$ solution under optimized process conditions, i.e. temperature $\left(150^{\circ} \mathrm{C}\right)$, time (30 $\mathrm{min}$ ) and $\mathrm{NaOH}$ concentration (3.1\% w/v) [28].

The microwave pretreatment with the use of a hydrotrope carried out in various process conditions caused changes in the composition of maize stillage biomass (Fig. 2). The use of water as an extraction solution during microwave treatment resulted in a partial extraction of organic matter from biomass. Water as the solvent did not have a major impact on the changes in cellulose concentration in biomass (average value around 37\%), but it did lower hemicellulose levels and caused an increase in lignin concentration as extraction progressed, which was due to the non-polar structure of lignins (Fig. 2). The increase in lignin concentration was associated with the research methodology and resulted from the use of a constant amount of biomass after microwave extraction to analyze the biomass composition. The extraction with $10 \% \mathrm{v} / \mathrm{v}$ NaCS resulted in changes in the biomass content. The concentration of cellulose increased and the content of hemicellulose and lignins decreased as extraction progressed and pressure increased (Fig. 2). After 30 minutes of extraction with $20 \% \mathrm{v} / \mathrm{v} \mathrm{NaCS}$ at 117 PSI this effect was enhanced: the concentration of cellulose, hemicellulose and lignins in biomass was $56.70 \pm 0.26 \%, 1.55 \pm 0.99 \%$, $14.97 \pm 0.32 \%$, respectively (Fig. 2). The maximum reduction of lignin concentration in these conditions ( $20 \% \mathrm{v} / \mathrm{v} \mathrm{NaCS}$ ) was about $44 \%$ compared to the process using only water, with the remaining process parameters unchanged. The results leave no doubt as to the suitability of microwave radiation combined with the use of NaCS for maize stillage biomass delignification. The delignification effect is visible 
despite the high biomass extractives (about 67\%). Because a constant amount of biomass is used to determine the components of lignocellulose, the effects of the lignin extraction process are somewhat covered up. To our knowledge, no reports describing microwave delignification using hydrotropes are available in the literature. However, many studies have confirmed that hydrotropes are effective in the extraction of lignins from plant biomass. Sodium xylene sulfonate ( $\mathrm{NaXS}$ ) used in the delignification process reduced lignin concentration by ca. $28 \%$ in eucalyptus biomass, by ca. $80 \%$ in sugar cane bagasse, by ca. $12 \%$ in wheat straw, and by ca. $47 \%$ in mixed birch and beech chips. Note that achieving this level of delignification required $30 \% \mathrm{NaXS}$ applied at $110^{\circ} \mathrm{C}(20 \mathrm{PSI})$ in sugar cane bagasse treatment or $>150^{\circ} \mathrm{C}(>68 \mathrm{PSI})$ in the treatment of other materials (wheat straw, a mixture of birch and beech chips, eucalyptus biomass); the exposure time was from 1 to 8 hours $[9,20,29,30]$. Studies demonstrated that NaCS could remove ca. 7 to $18 \%$ of lignins from distillery stillage biomass, ca. $30 \%$ from cotton stalks and ca. $52 \%$ from rice straw. Such reduction of lignin concentration was achieved for $20 \% \mathrm{v} / \mathrm{v} \mathrm{NaCS}$, at $131^{\circ} \mathrm{C}$ in the extraction lasting at least 1 hour $[19,21,31]$. As a result of the combined use of microwave radiation with $\mathrm{NaCS}$, as much as $44 \%$ reduction in lignin concentration was achieved in a very short time (at most $30 \mathrm{~min}$ ); none of the previous studies reported such a large reduction in such a short time. The usefulness of microwaves in the delignification process was also confirmed by other studies. For pretreatment in combination with microwave radiation, sulfuric acid, ionic liquids or basic salts with phosphoric acid are most often used. Microwaves together with $0.5 \% \mathrm{v} / \mathrm{v}$ sulfuric acid reduced the concentration of lignins in aloe biomass by up to $66 \%$ [22]. The combined action of ionic liquids together with microwave radiation at $130^{\circ} \mathrm{C}$ resulted in a nearly $80 \%$ reduction in lignin concentration in Miscanthus biomass and birch wood [24]. Pretreatment with microwaves and basic salts in phosphoric acid reduced the lignin concentration in rice straw by only 12 to $20 \%$ [16]. Similarly to our study, it was found that as a result of extraction of organic substances from plant biomass, the concentration of cellulose increased.

Biomass samples after hydrotropic microwave delignification were also subjected to enzymatic hydrolysis using a cellulolytic enzyme. The purpose of this research stage was to determine the effect of various process conditions of microwave hydrotropic delignification on glucose concentration after enzymatic hydrolysis of cellulose. Studies confirmed a high efficiency of hydrolysis of cellulose in maize stillage biomass after microwave hydrotropic delignification. The highest glucose concentration in the hydrolyzate was over $450 \mathrm{mg} / \mathrm{g}$ DW. This concentration was achieved after microwave treatment with NaCS under conditions providing the highest biomass reduction and the highest cellulose concentration, i.e. at $20 \% \mathrm{v} / \mathrm{v} \mathrm{NaCS}, 117 \mathrm{PSI}$ and 30 min exposure time (Fig. 3). Obtaining such a high glucose concentration per gram of biomass after pretreatment was not possible in our previous studies on the same raw material, which was subjected to barothermal treatment combined with diluted sulfuric acid [32]. In that experiment, a maximum of about $225 \mathrm{mg}$ glucose per gram of biomass was achieved. However, the use of dilute sulfuric acid together with microwave radiation resulted in ca. $270 \mathrm{mg}$ of glucose per gram of biomass after cellulose hydrolysis [11]. The susceptibility of biomass after hydrotropic treatment to enzymatic hydrolysis using cellulases was also demonstrated in studies on 
eucalyptus biomass. In eucalyptus biomass pretreated with NaXS, the conversion of cellulose to glucose was as high as about $80 \%$ [9].

\section{Optimization of enzymatic hydrolysis of cellulose in biomass after microwave hydrotropic delignification}

The next stage of the study after choosing the parameters of microwave hydrotropic delignification was the optimization of conditions for cellulose enzymatic hydrolysis. To this end, maize stillage biomass previously subjected to microwave hydrotropic treatment with $20 \% \mathrm{v} / \mathrm{v} \mathrm{NaCS}$ at $117 \mathrm{PSI}$ for 30 minutes was hydrolyzed using a cellulase preparation in acetate buffer $\mathrm{pH}$ 5.5. The hydrolysis process was analyzed for three biomass concentrations $(4,8,16 \% \mathrm{w} / \mathrm{v})$ and three enzyme dose levels $(1,2,4 \mathrm{FPU} / \mathrm{g}$ DW biomass). All experiments were run for 72 hours. The highest cellulose hydrolysis yield, about $80 \%$, was obtained for $4 \% \mathrm{w} / \mathrm{v}$ biomass concentration at the highest enzyme dose (4 FPU/g biomass) after 48 hours of the process (Fig. 4). Importantly, there were no statistically significant differences in cellulose hydrolysis yield between different biomass concentrations $(4,8,16 \% \mathrm{w} / \mathrm{v})$. at a given hour using a given dose of enzyme. A clear increase in cellulose hydrolysis yield in subsequent hours of the process was observed only for enzyme doses of 1 and 2 FPU/g biomass. The yield difference between the 24th and $72 \mathrm{nd}$ hour of hydrolysis at a dose of $1 \mathrm{FPU} / \mathrm{g}$ biomass ranged from about $30 \%$ for $4 \% \mathrm{w} / \mathrm{v}$ biomass concentration to about $20 \%$ for $16 \% \mathrm{w} / \mathrm{v}$ (Fig. 4). For the enzyme dose increased to $2 \mathrm{FPU} / \mathrm{g}$ biomass, the yield difference between 24th and 72 nd hour of hydrolysis was around $20 \%$ regardless of the biomass concentration used. At the highest enzyme dose, $4 \mathrm{FPU} / \mathrm{g}$ biomass, the yield of cellulose hydrolysis after 72 hours was only $8 \%$ higher than after 24 hours of the process, regardless of the biomass concentration in the medium (Fig. 4). Conditions that ensured high glucose level after 24 hours of hydrolysis, i.e. 16\% $\mathrm{w} / \mathrm{v}$ biomass concentration and enzyme dose of $4 \mathrm{FPU} / \mathrm{g}$ biomass, were selected for the next stage of the study. In our previous studies on the same raw material after baro-thermal treatment in a dilute sulfuric acid environment, the maximum yield of cellulose hydrolysis was $70 \%$ (it was lower by ca. $10 \%$ compared to this work), but only after 72 hours of the process [32]. In studies using corn stover, the highest cellulose hydrolysis yields were reported only at the highest enzyme concentration (40 mg protein per $1 \mathrm{~g}$ of glucan) and the highest biomass concentration $(20 \% \mathrm{w} / \mathrm{v})$. At lower enzyme concentrations, a significant decrease in hydrolysis yield was observed, even by $35 \%$ [33]. Also authors using rice straw as lignocellulosic raw material pointed out that obtaining the highest hydrolysis yield required precise optimization of process parameters. Properly selected enzyme and biomass concentrations resulted in up to $86 \%$ cellulose hydrolysis yield [34].

Evaluation of the suitability of hydrolyzate from maize stillage after microwave hydrotropic treatment and enzymatic hydrolysis for the production of cellulosic ethanol

At the last stage of the study, maize stillage biomass after microwave hydrotropic treatment and enzymatic hydrolysis was used to produce second generation ethanol. The hydrotropic microwave treatment with NaCS proved to be a very effective way of preparing maize stillage biomass for fermentation. It is worth noting that the proposed simplified pretreatment, involving only NaCS and 
microwaves (without additional acid treatment) allows to obtain a fermentation medium containing up to $80 \mathrm{~g}$ of glucose per liter, without condensing. This result was achieved after enzymatic hydrolysis of lignocellulose components present in $160 \mathrm{~g} / \mathrm{L}$ of biomass (Fig. 5). Eliminating the need to condense the substrate to obtain a high concentration of fermentable sugars is an important achievement of the proposed method. It suggests that microwave hydrotrope can improve the economics of cellulosic ethanol production. In the simplest experimental variant (MHF 1) only cellulolytic enzymes from Cellic ${ }^{8}$ CTec2 preparation were used to hydrolyze cellulose after pretreatment of biomass. In order to create optimal conditions for these biocatalysts, acetate buffer $\mathrm{pH} 5.5$ was used as the solvent. In other experimental variants (MHF2 and 3), in addition to Cellic ${ }^{\circledR}$ CTec2, hemicellulose degrading enzymes were used to increase the amount fermentable sugars, i.e. glucose and galactose. In these variants, acetate buffer pH 5.5 (MHF 2) or water pH 5.5 (MHF 3) was used as the solvent (Table 1). The lowest initial concentrations of glucose, ca. $69 \mathrm{~g} / \mathrm{L}$, as well as galactose and xylose, ca. $3.5 \mathrm{~g} / \mathrm{L}$, were observed in in the MHF 1 variant, because in this experiment only cellulolytic enzyme was applied (Table 1, Fig. 5, 6). When additional hemicellulose-degrading enzymes were used, a higher glucose concentration (ca. $79 \mathrm{~g} / \mathrm{L}$ ) was obtained, irrespective of the solvent used (buffer or water); galactose and xylose level also increased to ca. $6 \mathrm{~g} / \mathrm{L}($ Fig. 5,6$)$. Arabinose was not found in any of the fermentation media. It is worth emphasizing that fermentation media obtained after microwave hydrotropic treatment of maize stillage biomass did not contain 5-HMF, furfural and lignin degradation products such as syringaldehyde, transferulic acid, vanillin, 4-hydroxybenzoic acid (Table 2). The initial phase of fermentation in such media was not impeded, as observed in media with inhibitors. The undisturbed course of the initial fermentation phase resulted in complete bioconversion of glucose to ethanol after 48 hours of the process, in each experiment (Fig. 5). In experiments with Viscozyme ${ }^{\circledR}$ L (MHF 2 and 3), between 24 and $48 \mathrm{~h}$ of fermentation, only galactose was fermented, which led to a decrease in the sum of this sugar and xylose by ca. $0.5 \mathrm{~g} / \mathrm{L}$ (Fig. 6). Data collected during fermentation experiments suggest that is possible to achieve relatively high ethanol concentrations in lignocellulosic media, e.g. $35.54 \pm 1.42 \mathrm{~g} / \mathrm{L}$ for MHF 1 and 3 ok. $41.5 \mathrm{~g} / \mathrm{L}$ for MHF 2 (Fig. 5). Statistical analysis showed no significant differences between the initial glucose, galactose and xylose concentrations and the final ethanol concentration in MHF variants 2 and 3. The absence of fermentation inhibitors in the media combined with the high initial concentration of fermenting sugars resulted in a high concentration of ethanol and high fermentation yield. After 72 hours of the process, the ethanol yield in relation to the theoretical one was about $95 \%$, in all variants (Table 3 ). High yeast activity also exerted an effect on glycerol concentration in fermentation media (Fig. 6). This work demonstrated that maize stillage biomass after initial microwave hydrotropic treatment and enzymatic hydrolysis can be used to produce second generation ethanol. It is worth noting that achieving a high attenuation level did not require any supplementation with mineral substances or additional source of nitrogen, which otherwise would also affect the profitability of the process. 
Table 1

Charakterystyka podłoży fermentacyjnych przygotowanych w trakcie badań.

\begin{tabular}{|c|c|c|c|}
\hline Research variant & Solvent & $\mathrm{pH}$ & Enzyme preparation \\
\hline MHF 1 & $0.05 \mathrm{M}$ acetate buffer & 5.5 & Cellic $®$ CTec2 \\
\hline \multirow[t]{2}{*}{ MHF 2} & $0.05 \mathrm{M}$ acetate buffer & 5.5 & Cellic $®$ CTec2 \\
\hline & & & Viscozyme® L \\
\hline \multirow[t]{2}{*}{ MHF 3} & water & 5.5 & Cellic® CTec2 \\
\hline & & & Viscozyme ${ }^{\circledR} \mathrm{L}$ \\
\hline
\end{tabular}

Table 2

Początkowe stężenie 5-HMF, furfuralu oraz produktów degradacji lignin (syringaldehyde, trans-ferulic acid, vanillin, 4-hydroxybenzoic acid) w podłożach fermentacyjnych.

\begin{tabular}{|c|c|c|c|c|c|c|}
\hline \multirow[t]{2}{*}{$\begin{array}{l}\text { Research } \\
\text { variant }\end{array}$} & \multicolumn{4}{|c|}{$\begin{array}{l}\text { Initial concentration of phenolic compounds }(\mathrm{mg} / \mathrm{L}) \text { in } \\
\text { the fermentation medium }\end{array}$} & \multirow{2}{*}{$\begin{array}{l}\text { Initial } \\
\text { concentration } \\
\text { of } 5-H M F \\
\text { (mg/L) in the } \\
\text { fermentation } \\
\text { medium }\end{array}$} & \multirow{2}{*}{$\begin{array}{l}\text { Initial } \\
\text { concentration } \\
\text { of furfural } \\
\text { (mg/L) in the } \\
\text { fermentation } \\
\text { medium }\end{array}$} \\
\hline & syringaldehyde & $\begin{array}{l}\text { trans- } \\
\text { ferulic } \\
\text { acid }\end{array}$ & vanillin & $\begin{array}{l}\text { 4- } \\
\text { hydroxybenzoic } \\
\text { acid }\end{array}$ & & \\
\hline \multirow[t]{2}{*}{ MHF 1} & 0.00 & 0.00 & 0.00 & 0.00 & 0.00 & 0.00 \\
\hline & \pm 0.00 & \pm 0.00 & \pm 0.00 & \pm 0.00 & \pm 0.00 & \pm 0.00 \\
\hline \multirow[t]{2}{*}{ MHF 2} & 0.00 & 0.00 & 0.00 & 0.00 & 0.00 & 0.00 \\
\hline & \pm 0.00 & \pm 0.00 & \pm 0.00 & \pm 0.00 & \pm 0.00 & \pm 0.00 \\
\hline \multirow[t]{2}{*}{ MHF 3} & 0.00 & 0.00 & 0.00 & 0.00 & 0.00 & 0.00 \\
\hline & \pm 0.00 & \pm 0.00 & \pm 0.00 & \pm 0.00 & \pm 0.00 & \pm 0.00 \\
\hline
\end{tabular}


Table 3

Wydajność fermentacji alkoholowej względem wydajności teoretycznej po 72 godzinach procesu.

\begin{tabular}{|ll|}
\hline Research variant & $\begin{array}{l}\text { Yield of alcoholic fermentation } \\
\text { [\% of theoretical yield of glucose, galactose and xylose] after } 72 \text { hours }\end{array}$ \\
\hline MHF 1 & $\begin{array}{l} \pm .75 a \\
\pm 0.86\end{array}$ \\
& $94.69 \mathrm{a}$ \\
MHF 2 & 0.61 \\
& $95.33 \mathrm{a}$ \\
MHF 3 & \pm 0.57 \\
\hline The mean values given in columns with different letter index are significantly different $(a<0.05)$. \\
\hline
\end{tabular}

A review of the literature indicates the innovative nature of the proposed technological solution to use microwave radiation along with hydrotropes to process lignocellulosic biomass in ethanol production. Only a few studies attempted to use plant biomass after hydrotropic treatment at elevated temperature and pressure in the production of cellulosic ethanol. However, no previous study has achieved such a high concentration of fermentable sugars in the culture medium as in the present work. For example, the fermentation medium prepared from cotton stalks after hydrotropic treatment contained only $5.15 \mathrm{~g}$ of reducing sugars per liter [31]. The use of NaCS and NaXS in the processing of rice straw delivered $19.74 \mathrm{~g}$ and $10.22 \mathrm{~g}$ of glucose per liter of fermentation medium, respectively [21]. In previous studies, we used $\mathrm{NaCS}$ to pretreat maize stillage biomass. The process was carried out at $131^{\circ} \mathrm{C}$ for 1 hour. The final glucose concentration in the fermentation medium was about $63 \mathrm{~g} / \mathrm{L}$, but only after condensing [19]. Other authors reported that rice straw after hydrotropic treatment can be a source of cellulose susceptible to enzymatic hydrolysis and could provide an ethanol yield of 73 or $78 \%$ relative to the theoretical yield depending on the hydrotrope used. They pointed out that effective removal of hydrotropes from biomass is important, because residues of these compounds at higher concentrations might adversely affect the yeast metabolism [21]. Hydrotropic treatment can also be useful in the preparation of wheat straw in the butanol biosynthesis process: the use of NaXS provided ca. $23 \mathrm{~g} / \mathrm{L}$ glucose and, after conversion, over $9 \mathrm{~g}$ of butanol per liter [30].

\section{Conclusions}

This work was aimed at developing a new method of maize stillage biomass pretreatment. The method is based on microwave hydrotropic treatment with $\mathrm{NaCS}$ and can be used in the production of second generation ethanol. It was demonstrated that the proposed method was an effective way to delignify maize stillage biomass, which reduced lignin concentration by ca. $44 \%$. The stillage biomass after microwave treatment with NaCS was a good raw material for the production of second generation ethanol because it exhibited a high susceptibility to hydrolysis using cellulolytic enzymes. The hydrolysis 
yield reached $80 \%$. It is worth noting that the prepared media had a high glucose content of $80 \mathrm{~g} / \mathrm{L}$ (without concentration) and did not contain fermentation inhibitors such as 5-HMF, furfural or phenolic compounds. Elimination of fermentation inhibitors increased the rate of the fermentation process and led to a very high yield in relation to theoretical one, at the level of $95 \%$. Such a yield was obtained without supplementation with nutrients. Therefore, microwave hydrotropic treatment using NaCS is an effective way of preparing waste stillage biomass for the production of cellulosic ethanol and can contribute to the integration of the production of first and second generation ethanol.

\section{Materials And Methods}

\section{Materials}

The lignocellulosic raw material used in the study was centrifuged biomass of maize stillage

supplied by an agricultural distillery (Gospodarstwo Rolne in Radzicz, Poland) which uses the classic baro-thermal technology of releasing the starch with Henze steamer. Before the experiments the material was dried at $60^{\circ} \mathrm{C}$ until constant weight, ground and sieved through a $1 \mathrm{~mm}$ sieve. The raw material dry weight (DW) was $5.06 \pm 0.15 \%$. The content of cellulose, hemicellulose and lignins was $34.15 \pm 0.28 \%$, $13.56 \pm 0.48 \%$ and $16.23 \pm 0.67 \%$, respectively. Analytical and HPLC grade reagents used in the study were supplied by Merck® (Darmstadt, Germany). The standards used in the chromatographic analyzes were HPLC grade, supplied by Sigma-Aldrich ${ }^{\circledR}$ (St. Louis, Missouri, United States). Sodium cumene sulfonate (NaCS) was used as the hydrotrope, in the form of a $40 \%$ v/v Stepanate ${ }^{\circledR}$ SCS 40 preparation supplied by the Stepan Company (Northfield, Illinois, United States).

\section{Enzymatic preparations}

Cellic ${ }^{\circledR}$ CTec2 2 preparation (Novozymes, Franklinton, NC, USA) containing a complex of cellulolytic enzymes with $75 \mathrm{FPU} / \mathrm{mL}$ activity was used in the enzymatic hydrolysis of cellulose. The preparation was applied according to the manufacturer's instructions at $\mathrm{pH} 5.5$ and $50{ }^{\circ} \mathrm{C}$. In the preparation of fermentation media, Viscozyme ${ }^{\circledR}$ L (Novozymes, Bagsvaerd, Denmark) was additionally used. This preparation exhibits endo- $\beta$-glucanase (xylanase, cellulase, hemicellulase) activity, $100 \mathrm{FBG} / \mathrm{g}$, and hydrolyses $\beta$ - $(1,3)$ - or $\beta-(1,4)$-glycosidic linkages in $\beta$-D-glucans. It was used according to the manufacturer's instructions at a dose of $8 \mathrm{FGB} / \mathrm{g} \mathrm{DW}$, at $\mathrm{pH} 5.5$ and $50^{\circ} \mathrm{C}$.

\section{Yeast}

The alcoholic fermentation process was carried out using an active preparation of dried yeast $S$. cerevisiae strain Ethanol Red (Lesaffre Advanced Fermentations). Yeast was applied in the form of yeast milk $\left(1.25 \pm 0.12 \times 10^{9} \mathrm{CFU} / \mathrm{mL}\right.$, cell viability $\left.94.3 \pm 0.5 \%\right)$ prepared by suspending $1 \mathrm{~g}$ of the preparation in $10 \mathrm{ml}$ of sterile $0.9 \% \mathrm{v} / \mathrm{v} \mathrm{NaCl}$ at $30^{\circ} \mathrm{C}$ (according to the manufacturer's instructions). The dose of yeast was $2 \mathrm{~g}$ of preparation per one liter of cellulosic fermentation medium.

\section{Research stages}




\section{Selection of process conditions of microwave hydrotropic extraction}

In the first stage of research, we examined the impact of the conditions of microwave hydrotropic extraction on biomass extractives, enzymatic hydrolysis of cellulose and the composition of biomass. The effects of hydrotropic extraction under microwave conditions were evaluated for different pressure values $(39,78,117 \mathrm{PSI})$, exposure time $(10,20,30$ minutes) and NaCS concentration $(0,10,20 \% \mathrm{v} / \mathrm{v})$, with constant microwave generator power at $300 \mathrm{~W}$. The experiment included 27 variants of microwave hydrotropic extraction. The analysis began by placing $1 \mathrm{~g} \mathrm{DW}(1.05 \mathrm{~g})$ of a given type of biomass in a HP500 plus Teflon container and adding $20 \mathrm{~mL}$ of extraction solution (5\% biomass concentration). The extraction process was carried out in the MARS 5 microwave mineralizer (by CEM Corporation) to control the pressure conditions. After the extraction, the solution was cooled to ca. $60{ }^{\circ} \mathrm{C}$ and filtered through a polyamide filter membrane with a pore size of $50 \mu \mathrm{m}$. The biomass was then rinsed with $150 \mathrm{~mL}$ of hot distilled water to remove residual extraction solution, and dried to constant weight (DW) at $130{ }^{\circ} \mathrm{C}$ using a moisture analyzer. The biomass extractives were calculated based on the difference in sample weight before and after hydrotropic extraction [22]. The analysis was performed in 9 replications to obtain enough biomass necessary to calculate the biomass extractives and to obtain the raw material for the analysis of lignocellulose composition and to carry out the enzymatic hydrolysis process. After microwave extraction, the biomass was dried up and then used to determine the content of cellulose, hemicellulose and lignins. The analysis of the impact of the conditions of microwave hydrotropic extraction on the efficiency of enzymatic hydrolysis of cellulose began with placing $1 \mathrm{~g} \mathrm{DW}(1.05 \mathrm{~g})$ of the biomass after extraction in a $250 \mathrm{~mL}$ conical flask and adding $25 \mathrm{~mL} 0.05 \mathrm{M}$ acetate buffer $\mathrm{pH} 5.5$ ( $4 \%$ biomass concentration). The solution was then placed in a shaking water bath at $50^{\circ} \mathrm{C}, 5 \mathrm{FPU}$ Cellic ${ }^{\circledR}$ CTec 2 cellulolyte preparation $(65 \mu \mathrm{L})$ was added and shaken for 72 hours. Glucose concentration was measured every 24 hours by HPLC. Analysis of the biomass composition and the impact of the hydrotropic microwave extraction conditions on the amount of glucose obtained from the biomass after the enzymatic hydrolysis of cellulose was carried out in triplicate.

\section{Selection of conditions for cellulose enzymatic hydrolysis}

Optimization of the enzymatic hydrolysis process of cellulose was carried out on biomass after microwave hydrotropic extraction under the following conditions: pressure $117 \mathrm{PSI}$, extraction time 30 minutes, NaCS concentration $20 \% \mathrm{v} / \mathrm{v}$, microwave generator power $300 \mathrm{~W}$. Optimization of hydrolysis conditions included selection of biomass concentration $(4,8,16 \% \mathrm{w} / \mathrm{v})$ and enzyme amount $(1,2,4$ $\mathrm{FPU} / \mathrm{g}$ DW biomass) in a $72 \mathrm{~h}$ process. The analysis began by placing 1,2 or $4 \mathrm{~g} \mathrm{DW}(1 \mathrm{~g} \mathrm{DW}=1.05 \mathrm{~g})$ biomass after microwave hydrotropic extraction in $250 \mathrm{~mL}$ conical flasks and adding $25 \mathrm{~mL} 0.05 \mathrm{M}$ acetate buffer $\mathrm{pH}$ 5.5. Then the solution was placed in a shaking water bath at $50^{\circ} \mathrm{C}$, Cellic ${ }^{\circledR} \mathrm{CTec} 2$ cellulolytic preparation was added (assuming that $13 \mu \mathrm{L}$ corresponded to $1 \mathrm{FPU} / \mathrm{g} \mathrm{DW}$ ). The hydrolysis lasted 72 hours. Glucose concentration was measured every 24 hours by HPLC. All analyzes were performed in triplicate. Based on glucose concentration, the yield of cellulose hydrolysis was determined as follows: 


$$
\text { Yield of hydrolysis }[\backslash \%]=\frac{\mathrm{C}_{\mathrm{Glu}}}{1.111 \times \mathrm{C}_{\mathrm{Cel}} \times \mathrm{C}_{\mathrm{Biom}}} \times 100
$$

where $\mathrm{C}_{\mathrm{Glu}}$ is the concentration of glucose (grams per liter) in the sample, $\mathrm{C}_{\mathrm{Cel}}$ is the cellulose content in biomass (per 1 gram of dry weight), $\mathrm{C}_{\mathrm{Biom}}$ is the initial biomass content (grams per liter) [33].

Assessment of the suitability of microwave hydrotropic extraction in the production of ethanol from maize stillage biomass

Alcoholic fermentation was carried out using stillage biomass after microwave hydrotropic extraction under the conditions selected in the first stage of the study (pressure $117 \mathrm{PSI}$, extraction time 30 minutes, NaCS concentration $20 \% \mathrm{v} / \mathrm{v}$, microwave generator power $300 \mathrm{~W}$ ). The biomass after hydrotropic treatment was subjected to enzymatic hydrolysis using Cellic ${ }^{\circledR}$ CTec2 preparation under the conditions selected in the second stage of the study, ensuring the highest glucose concentration during a $24 \mathrm{~h}$ process, i.e. biomass concentration $16 \% \mathrm{w} / \mathrm{v}$ and $4 \mathrm{FPU} / \mathrm{g}$ DW. In subsequent research variants, an additional Viscozyme ${ }^{\circledR}$ L preparation was applied for a more complete use of polysaccharide components in the fermentation process. Alcoholic fermentation was carried out in three variants (Table 1). As the fermentation environment we used acetate buffer, to provide optimal conditions for enzymatic hydrolysis and fermentation, or tap water to simulate the conditions of the technological process. Preparation of the fermentation medium was started by placing $8 \mathrm{~g}$ DW of stillage biomass in a $250 \mathrm{~mL}$ conical flask and adding $50 \mathrm{~mL}$ of the appropriate solvent (depending on the test variant). When water was used, the $\mathrm{pH}$ was adjusted to 5.5 with $0.1 \mathrm{M} \mathrm{NaOH}$ and $0.1 \mathrm{M} \mathrm{HCl}$. Then the Cellic $\AA \mathrm{CTec} 2$ enzyme preparation was added, 4 FPU/g DW. Viscozyme® ${ }^{\circledR}, 8$ FGB/g DW, was additionally applied in selected experiments (Table 1). Enzymatic hydrolysis was carried out in a shaking water bath at $80 \mathrm{rpm}$ and $50{ }^{\circ} \mathrm{C}$ for 24 hours. After the hydrolysis, the solution was cooled down to $35^{\circ} \mathrm{C}$ and inoculated with yeast milk. Then the flask was sealed with a fermentation tube filled with glycerin and incubated at $35^{\circ} \mathrm{C}$ for 72 hours. The composition of the fermentation medium was examined by HPLC before fermentation and every 24 hours of the process. The analysis included determining the concentration of sugars, glycerol, organic acids, ethanol, phenolic compounds, 5-HMF and furfural. Fermentation tests were carried out in triplicate. Fermentation yield after 72 hours of the process was calculated based on the concentration of ethanol and sugars in the fermentation medium according to the formula:

$$
\text { Fermentation yield }[\backslash \%]=\frac{\mathrm{E}}{\mathrm{SC} \times 0.511} \times 100
$$

2

where $\mathrm{E}$ is the concentration of ethanol (grams per liter) after 72 hours of the process, SC is the initial content of sugars (glucose, xylose/galactose, in grams per liter), 0.511 is the value representing the theoretical ethanol yield from polysaccharides [35]. 


\section{Analytical methods}

\section{Characterization of native and pretreated distillery stillages}

Determination of cellulose, hemicellulose and lignins was performed using the FOSS Fibertec $8000 \AA$ system. The analysis was based on the extraction and weighing of neutral detergent fiber (NDF), acid detergent fiber (ADF) and acid detergent lignin (ADL). Measurements were carried out in accordance with the device manufacturer's methodology, and according to ISO 13906: 2008 and ISO 16472: 2006.

\section{Determination of carbohydrates, acetic acid, glycerol and ethanol in fermentation medium}

The content of sugars (glucose, galactose and xylose, arabinose), acetic acid, glycerol and ethanol in the samples after enzymatic hydrolysis of cellulose and in fermentation media was analyzed by highperformance liquid chromatography (HPLC-RID). Before analysis, the samples were diluted 5 -fold in the mobile phase, i.e. $5 \mathrm{mM} \mathrm{H}_{2} \mathrm{SO}_{4}$, and filtered through a $0.45 \mu \mathrm{m}$ membrane filter. The analysis was carried out using an Agilent Technologies ${ }^{\circledR}$ model 1260 chromatograph equipped with a refractometric detector. The separation was performed on a Hi-Plex H column (Agilent Technologies $\circledast$ ) equipped with a dedicated guard column, with a mobile phase flow of $0.6 \mathrm{~mL} / \mathrm{min}$ at $60^{\circ} \mathrm{C}$. Quantitative analysis was performed using external standards (ESTD). Because Hi-Plex $\mathrm{H}$ column does not allow for effective separation of xylose and galactose peaks, the concentration of these sugars is given as their sum.

\section{Determination of 5-HMF, furfural and phenolic compounds as lignin degradation products}

Phenolic compounds, i.e. vanillin, 4-hydroxybenzoic acid, syringaldehyde, trans ferulic acid (as lignin degradation products) as well as 5-HMF and furfural were also determined in fermentation media. The analysis was performed using the Agilent Technologies ${ }^{\circledR}$ HPLC system, model 1260, equipped with a diode detector (HPLC-DAD). Chromatographic separation was carried out on a ZORBAX Eclipse Plus C18 $(4.6 \times 100 \mathrm{~mm}, 3.5 \mu \mathrm{m})$ column (Agilent Technologies ${ }^{\circledR}$ ) using $0.3 \%$ acetic acid $(70 \%)$ and methanol $(30 \%)$ as mobile phase, at a flow rate of $0.5 \mathrm{~mL} / \mathrm{min}$ and $30^{\circ} \mathrm{C}$. 5-HMF, furfural, 4-hydroxybenzoic acid and vanillin were detected at $280 \mathrm{~nm}$. Syrup aldehyde and trans-ferulic acid were detected at $320 \mathrm{~nm}$ [36]. Quantitative analysis was performed using external standards (ESTD).

\section{Statistical analysis}

All laboratory analyzes were performed in triplicate. Statistical analysis was carried out using the Statistica software ver. 12 (analysis of variance, determination of SD). ANOVA test and HSD Tukey's test were applied at the significance level of $a<0.05$.

\section{Declarations' Section}


Not applicable.

\section{Consent for publication}

Not applicable.

\section{Availability of data and materials}

Not applicable.

\section{Abbreviations}

5-HMF

5-hydroxymethylfurfural; NaCS: sodium cumene sulfonate; NaXS:sodium xylene sulfonate; DW:dry weight; HPLC:high-performance liquid chromatography; ANOVA:analysis of variance; DAD:diode array detector.

\section{Declarations}

\section{Competing interests}

The authors declare that they have no competing interests.

\section{Funding}

This study was supported by the Polish Minister of Science and Higher Education, under the program "Regional Initiative of Excellence" in 2019-2022 (Grant No. 008/RID/2018/19).

\section{Authors' contributions}

DM participated in the design of the experiments, performed of the experiments and contributed to manuscript writing. GK supervised the research and participated in the design of the experiments and manuscript writing. All authors have contributed to scientific discussion. All authors read and approved the final manuscript.

\section{Acknowledgements}

Not applicable.

\section{References}


1. Balat M. Production of bioethanol from lignocellulosic materials via the biochemical pathway: $A$ review. Energ Convers Manage. 2011;52:858-575.

2. Sarkar N, Ghosh SK, Bannerjee S, Aikat K. Bioethanol production from agricultural wastes: An overview. Renew Energ. 2012;37:19-27.

3. Mood SH, Golfeshan AH, Tabatabaei M, Jouzani GS, Najafi GH, Gholami M, Ardjmand M. Lignocellulosic biomass to bioethanol, a comprehensive review with a focus on pretreatment. Renew Sust Energ Rev. 2013;27:77-93.

4. Jonsson LJ, Alriksson B, Nilvebrant NO. Bioconversion of lignocellulose: inhibitors and detoxification. Biotechnol Biofuels. 2013;6(16):1-10.

5. Noureddini H, Byun J. Dilute acid pretreatment of distillers' grains and corn fiber. Bioresource Technol. 2010;101:1060-7.

6. Camasasca L, Ramirez MB, Guigou M, Ferrari MD, Lareo C. Evaluation of dilute acid and alkaline pretreatments, enzymatic hydrolysis and fermentation of napiergrass for fuel ethanol production. Biomass Bioenerg. 2015;74:193-201.

7. Smuga-Kogut M, Walendzik B, Szymanowska-Powałowska D, Kobus-Cisowska J, Wojdalski J, Wieczorek M, Cielecka-Piontek J. Comparison of bioethanol preparation from triticale straw using the ionic liquid and sulfate methods. Energies. 2019;12:1155.

8. Li C, Knierim B, Manisseri C, Arora R, Scheller HV, Aure M, Vogel KP, Simmons BA, Singh S. Comparison of dilute acid and ionic liquid pretreatment of switchgrass: Biomass recalcitrance, delignification and enzymatic saccharification. Bioresource Technol. 2010;101:4900-6.

9. Mou H, Wu S. Comparison of organosolv and hydrotropic pretreatments of eucalyptus for enhancing enzymatic saccharification. Bioresource Technol. 2016;220:637-40.

10. Bundhoo ZMA. Microwave-assisted conversion of biomass and waste materials to biofuels. Renew Sust Energ Rev. 2018;82:1149-77.

11. Mikulski D, Kłosowski G, Menka A, Koim-Puchowska B. Microwave-assisted pretreatment of maize distillery stillage with the use of dilute sulfuric acid in the production of cellulosic ethanol. Bioresource Technol. 2019;278:318-28.

12. Mikulski D, Kłosowski G. Microwave-assisted dilute acid pretreatment in bioethanol production from wheat and rye stillages. Biomass Bioenerg. 2020;136:105528.

13. Amini N, Haritos VS, Tanksale A. Microwave assisted pretreatment of eucalyptus sawdust enhances enzymatic saccharification and maximizes fermentable sugar yield. Renew Energ. 2018;127:653-60.

14. Ethaib S, Omar R, Mazlina M, Radiah A, Syafiie S, Harun MY. Effect of microwave-assisted acid or alkali pretreatment on sugar release from Dragon fruit foliage. International Food Research Journal. 2016;23:149-54.

15. Germec M, Demirel F, Tas N, Ozcan A, Yilmazer C, Onuk Z, Turhan I. Microwave-assisted dilute acid pretreatment of different agricultural bioresources for fermentable sugar production. Cellulose. 2017;24:4337-53. 
16. Bhardwaj N, Kumar B, Verma P. Microwave-assisted pretreatment using alkali metal salt in combination with orthophosphoric acid for generation of enhanced sugar and bioethanol. Biomass Conversion Biorefinery. 2020. https://doi.org/10.1007/s13399-020-00640-1.

17. Dhapte V, Mehta P. Advances in hydrotropic solutions: An updated review. St Petersburg Polytechnical University Journal: Physics Mathematics. 2015;1:424-35.

18. Devendra LP, Kumar KM, Pandey A. Evaluation of hydrotropic pretreatment on lignocellulosic biomass. Bioresource Technol. 2016;213:350-8.

19. Mikulski D, Kłosowski G. Hydrotropic pretreatment on distillery stillage for efficient cellulosic ethanol production. Bioresource Technol. 2020;300:122661.

20. Olsson J, Novy V, Nielsen F, Wallberg O, Galbe M. Sequential fractionation of the lignocellulosic components in hardwood based on steam explosion and hydrotropic extraction. Biotechnol Biofuels. 2019;12:1.

21. Devendra LP, Pandey A. Hydrotropic pretreatment on rice straw for bioethanol production. Renew Energ. 2016;98:2-8.

22. Rajeswari G, Arutselvy B, Jacob S. Delignification of aloe vera rind by mild acid associated microwave pretreatment to persuade enhanced enzymatic saccharification. Waste Biomass Valori. 2019. https://doi.org/10.1007/s12649-019-00830-7.

23. Alexander RA, Innasimuthu GM, Rajaram SK, Jeganathan PM, Somasundarar SC. Process optimization of microwave-assisted alkali pretreatment for enhanced delignification of Prosopis juliflora biomass. Environ Prog Sustainable Energy. 2018;39:13289.

24. Kohli K, Katuwal S, Biswas A, Sharmaa BK. Effective delignification of lignocellulosic biomass by microwave assisted deep eutectic solvents. Bioresource Technol. 2020;303:122897.

25. Muley PD, Mobley JK, Tong X, Novak B, Stevens J, Moldovan D, Shi J, Boldor D. Rapid microwaveassisted biomass delignification and lignin depolymerization in deep eutectic solvents. Energ Convers Manage. 2019;196:1080-8.

26. Balasubramanian D, Srinivas V, Gaikar VG, Sharma MM. Aggregation behaviour of hydrotropes in aqueous solutions. J Phys Chem. 1989;93:3865-70.

27. Dávila I, Gullón P, Labidi J, Budarin V. Assessment of the influence of the temperature in the microwave-assisted alkaline delignification of vine shoots. Chem Eng Trans. 2018;70:1687-92.

28. Dávila I, Remón J, Gullón P, Labidi J, Budarin V. Production and characterization of lignin and cellulose fractions obtained from pretreated vine shoots by microwave assisted alkali treatment. Bioresource Technol. 2019;289:121726.

29. Ansari KB, Gaikar VG. Green hydrotropic extraction technology for delignification of sugarcane bagasse by using alkybenzene sulfonates as hydrotropes. Chem Eng Sci. 2014;115:157-66.

30. Qi G, Xiong L, Li H, Huang Q, Luo M, Tian L, Chen X, Huang C, Chen X. Hydrotropic pretreatment on wheat straw for efficient biobutanol production. Biomass Bioenerg. 2019;122:76-83. 
31. Karthyani S, Pandey A, Devendra LP. Delignification of cotton stalks using sodium cumene sulfonate for bioethanol production. Biofuels. 2017. doi:10.1080/17597269.2017.1370884.

32. Mikulski D, Kłosowski G. Efficiency of dilute sulfuric acid pretreatment of distillery stillage in the production of cellulosic ethanol. Bioresource Technol. 2018;268:424-33.

33. Rana V, Rana D, Ahring BK. Process modelling of enzymatic hydrolysis of wet-exploded corn stover. Bioenerg Res. 2014;7:450-9.

34. Jeya M, Zhang Y-W, Kim I-W, Lee J-K. Enhanced saccharification of alkali-treated rice straw by cellulase from Trametes hirsuta and statistical optimization of hydrolysis conditions by RSM. Bioresource Technol. 2009;100:5155-61.

35. Berłowska J, Pielech-Przybylska K, Balcerek M, Dziekońska-Kubczak U, Patelski P, Dziugan P, Kręgiel D. Simultaneous saccharification and fermentation of sugar beet pulp for efficient bioethanol production. Biomed Res Int. 2016. http://dx.doi.org/10.1155/2016/3154929.

36. Cho DH, Lee YJ, Um Y, Sang B-I, Kim YH. Detoxification of model phenolic compounds in lignocellulosic hydrolysates with peroxidase for butanol production from Clostridium beijerinckii. Appl Microbiol Biotechnol. 2009;83:1035-43.

\section{Figures}

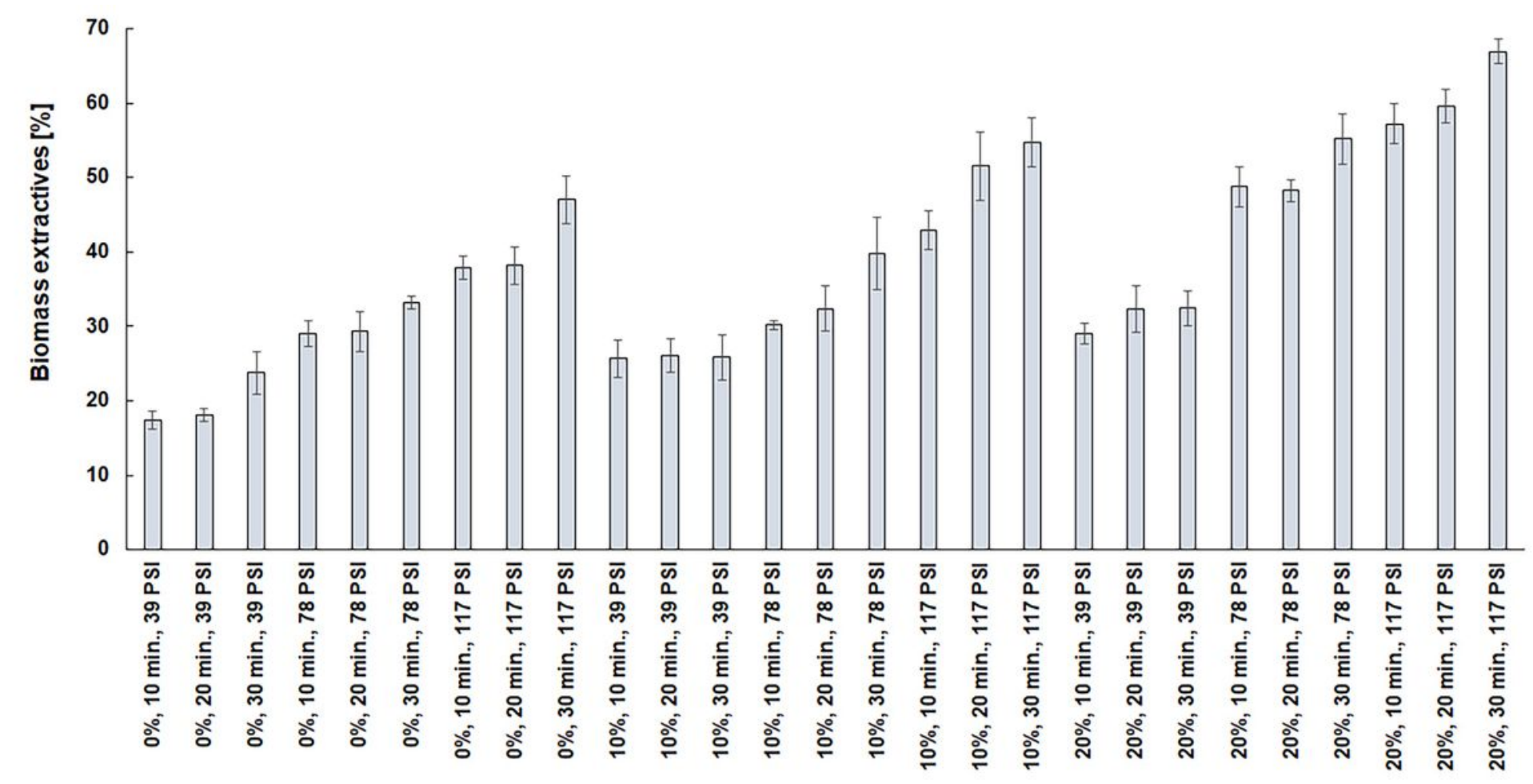

\section{Figure 1}

The effect of $\mathrm{NaCS}$ concentration, pretreatment time and pressure on biomass extractives after microwave-assisted hydrotropic pretreatment of maize distillery stillage. 


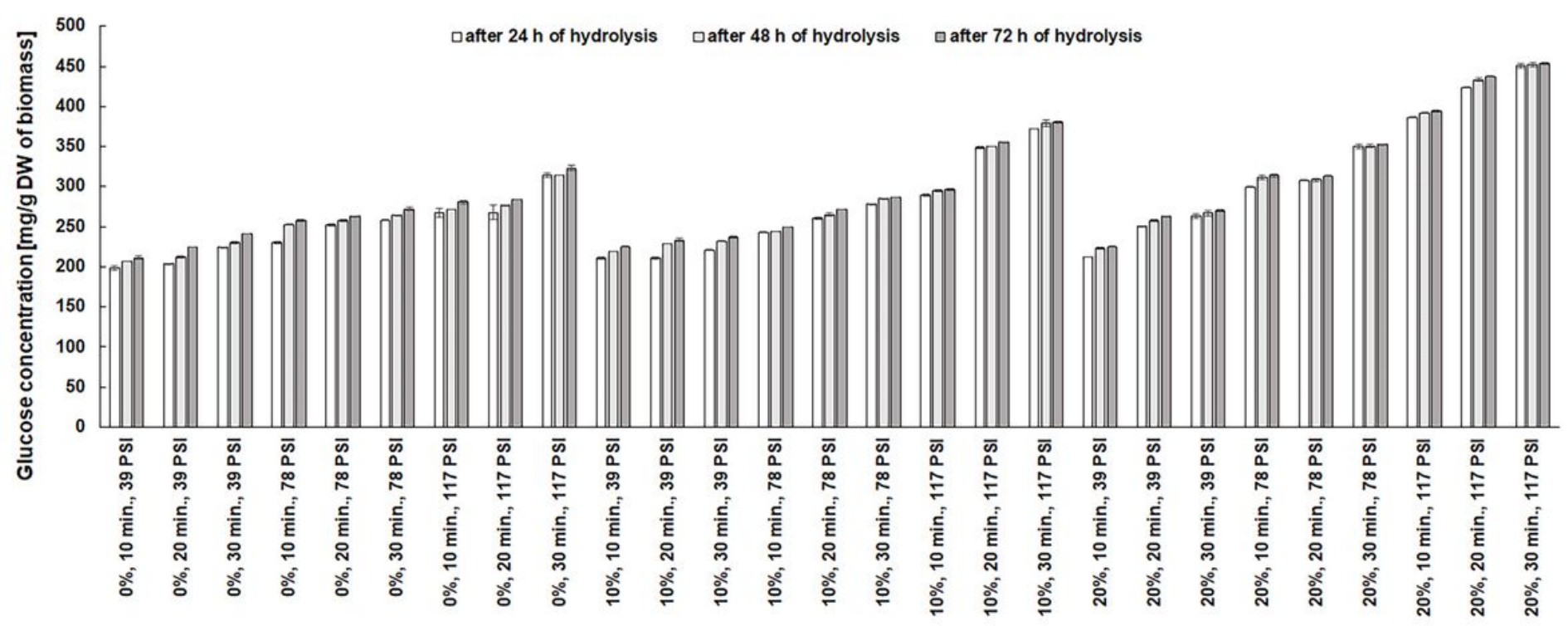

Figure 2

The effect of NaCS concentration, pretreatment time and pressure on biomass composition after microwave-assisted hydrotropic pretreatment of maize distillery stillage.

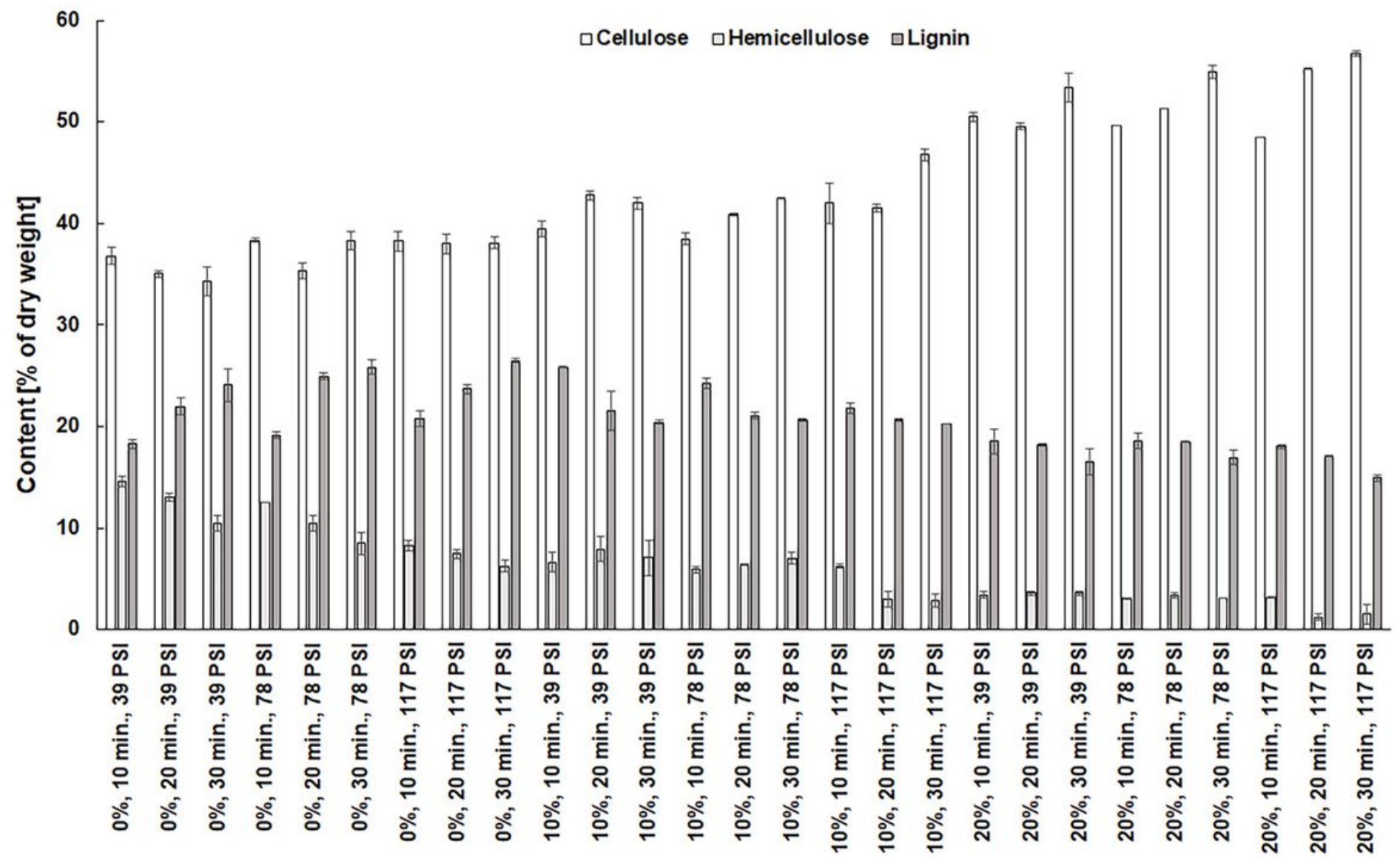

Figure 3 
The effect of NaCS concentration, pretreatment time and pressure on glucose concentration obtained by the enzymatic hydrolysis of cellulose after microwave-assisted hydrotropic pretreatment of maize distillery stillage.
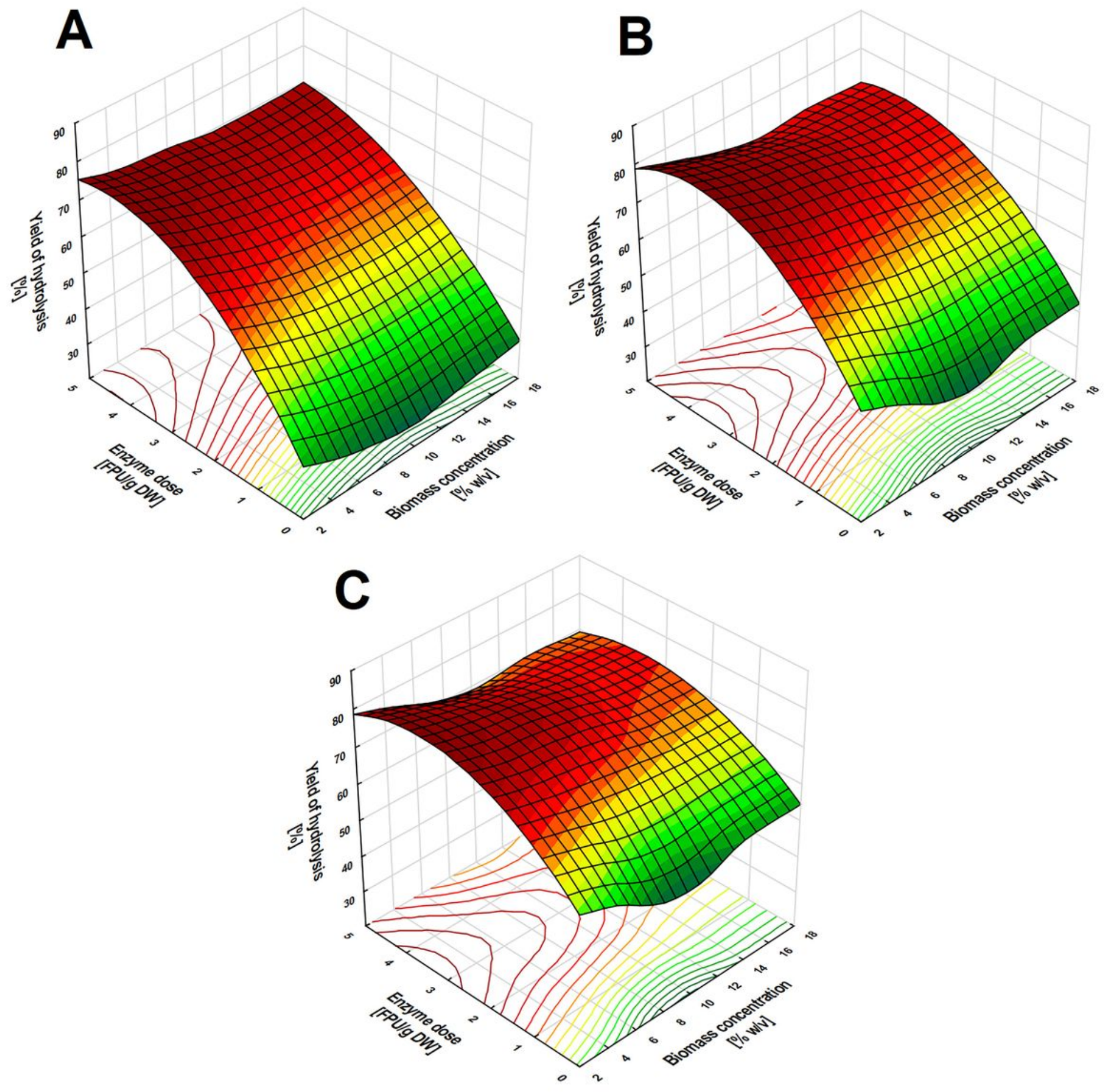

\section{Figure 4}

Response surface plot showing the effect of the interaction between maize stillage biomass concentration and enzyme dose on hydrolysis yield after 24 (A), 48 (B), and 72 (C) hours of enzymatic hydrolysis. 


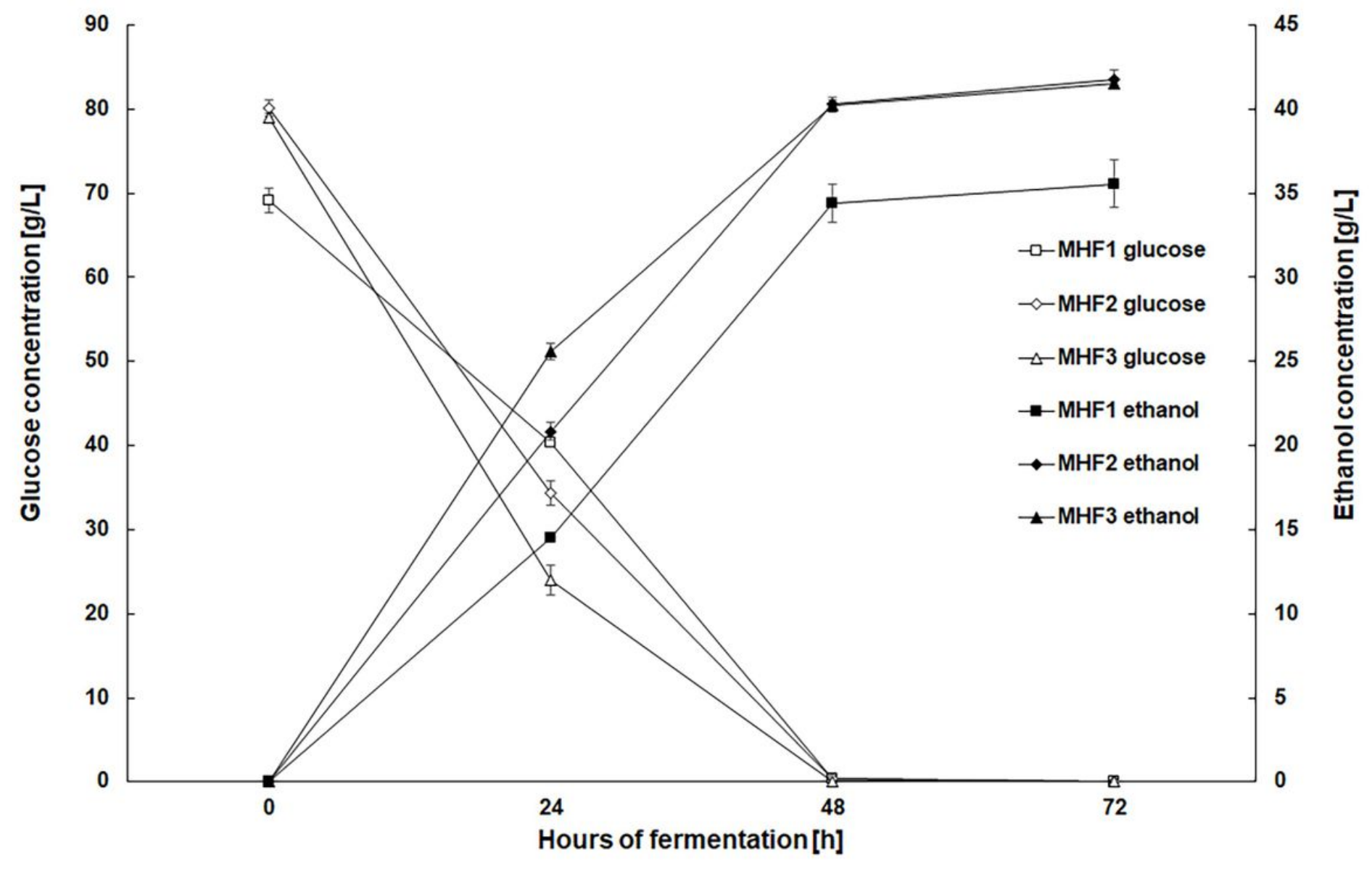

Figure 5

Changes in the concentration of glucose (open tags) and ethanol (closed tags) during alcoholic fermentation. 


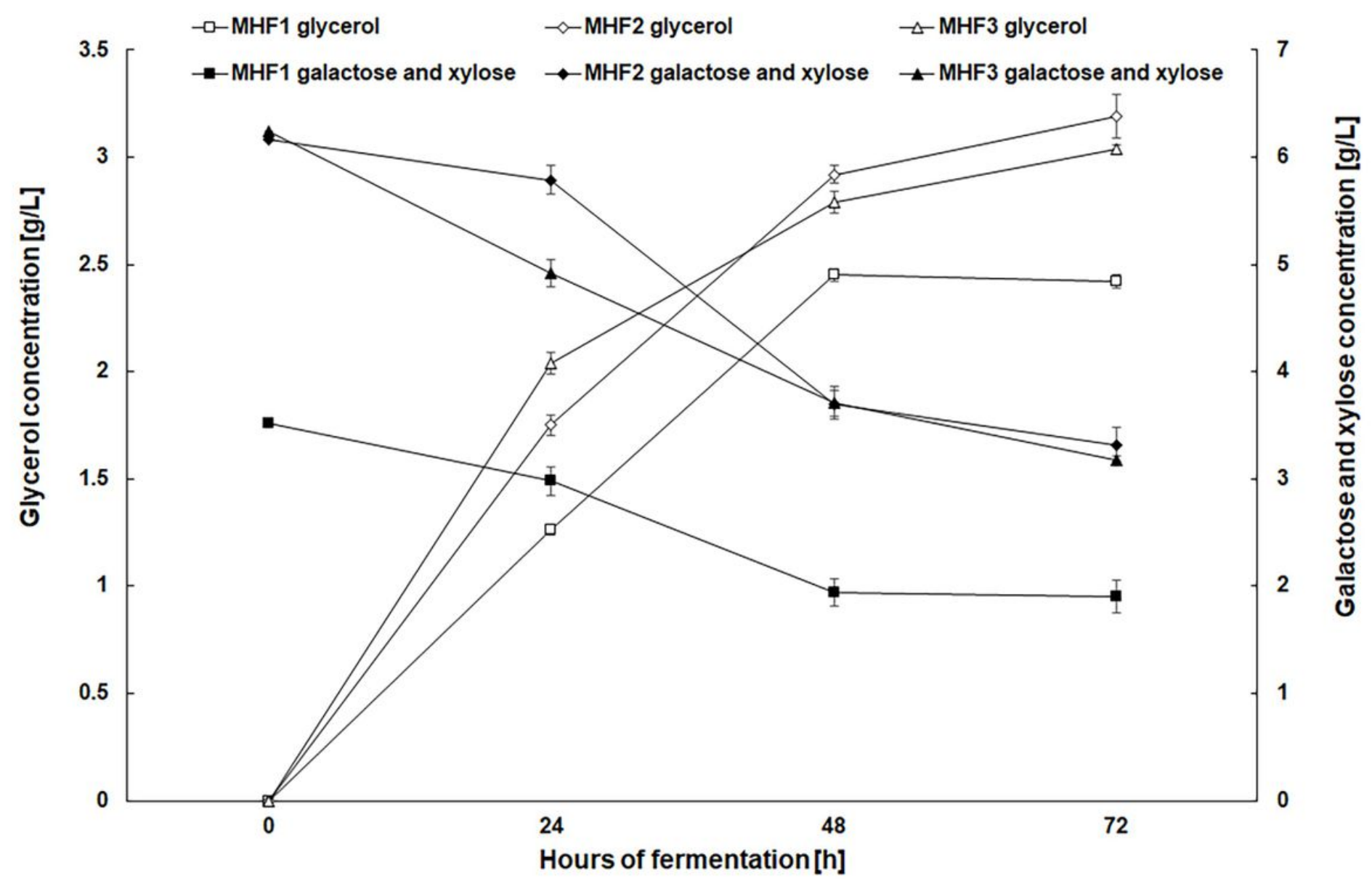

Figure 6

Changes in the concentration of glycerol (open tags), galactose and xylose (closed tags) during alcoholic fermentation. 